\title{
Preface to John W. Morse Special Issue of Aquatic Geochemistry
}

\author{
Fred T. Mackenzie · Alfonso Mucci • George W. Luther III
}

Received: 5 July 2011/Accepted: 6 July 2011/Published online: 24 August 2011

(C) Springer Science+Business Media B.V. 2011

This Special Volume of Aquatic Geochemistry is dedicated to the memory of Professor John W. Morse, a world leader in chemical oceanography and marine geochemistry, especially carbonate geochemistry, in the Department of Oceanography at the Texas A\&M University (see http://oceanz.tamu.edu/Directory/Faculty/Chem/morse.html; see also Mackenzie et al. 2010). John passed away unexpectedly Monday, November 23, 2009, at the St Joseph Regional Health Center in Bryan, Texas, of medical complications arising originally from lung cancer and surgery. Although John spent most of his academic career at A\&M, he also was on the oceanography and chemistry faculties of Florida State University from 1973 to 1976 and the faculty of the Division of Marine and Atmospheric Chemistry, Rosenstiel School of Marine and Atmospheric Science, at the University of Miami from 1976 to 1981. John was one of a small cadre of geochemists (now more popularly called bio-geochemists) of his vintage who was truly holistic and global in approaches to scientific research. He worked well in the laboratory and field and had the natural ability to take his laboratory and field observations and interpret them in the context of a sound theoretical foundation. John published one major book and more than 150 research papers during his career. He was in the top $0.5 \%$ of the most highly cited authors in Earth science fields and was ranked among the top 200 Earth scientists in Earth Science A to Z in 2003 (Fig. 1).

John played a visionary and central coordinating role in the United States and international geochemistry activities. In addition, his scientific rigor and directness were an example to younger scientists, many of whom have gone on to important research or policy-making positions in the United States and elsewhere. There is a small sign that appeared in the laboratory of FTM's friend and colleague Roland Wollast at the Université Libre de Bruxelles some years ago. It symbolizes John's approach to being a scientist and also that of three of his respected mentors and inspirations in the field of geochemistry, Robert M. Garrels, Robert A. Berner, and Roland Wollast-reflecting scientists with the highest standards of hard work and dedication but also individuals who had a sense of humor and recognized that what we do as scientists should be fun and contribute to the betterment of the society. It reads:

F. T. Mackenzie $(\bowtie) \cdot$ A. Mucci · G. W. Luther III University of Hawaii at Manao, Honolulu, HI, USA e-mail: fredm@earth.northwestern.edu 
Fig. 1 John W. Morse, the scholar and gentleman

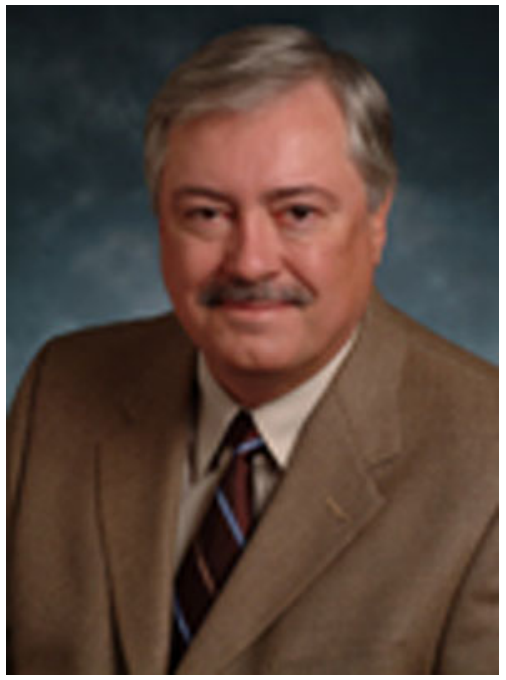

Theory is when one knows everything but nothing works.

Practice is when everything works but no one knows why.

Here, theory and practice are joined, nothing works and we do not know why.

John's enthusiasm for science extended into his personal relationships with his students, colleagues, and friends. There was never a moment when you could not have a stimulating talk with John, not only about science but also about life in general. He was a master of getting at the heart of any problem. John was an epicurean at heart; he loved good food, spirits, and company. He often hauled his friends and graduate students to the finest restaurants for long-winded meals (Fig. 2).

At the time of his death, John's major research interests lay in the role of surface exchange reactions and nutrient cycling in estuaries; benthic biogeochemical studies of organism-sediment interactions using microelectrodes; geochemistry of sedimentary sulfides and their influence on metal toxicity; Pitzer equation-based ionic models for natural waters; carbonate mineral reaction kinetics; and the hydrochemistry and formation of whitings in the Bahamas (Fig. 3).

John's ashes were scattered in early 2011 in the sea off of the Bahamas, reflecting his life-long association with the sea and this area and his love and dedication to the field of oceanography. John is survived by his loving wife, Sandy Morse; daughter, Angela Morse; sister, Kristi Morse; mother-in-law, Mildred Key; brother- and sister-in-law, Ronnie and Hazel Key; and niece, Jacqueline Henry. With John's passing, the world has lost a fine gentleman and scholar and a friend to many. All will dearly miss him (Fig. 4).

The contributors to this special issue are all former students, colleagues, and friends of John's, who wish to honor his memory in the spirit of what John loved most and in appreciation of his influence and mentorship to us all. Because John was such an eclectic scientist, the papers in this volume cover a wide range of subjects and are difficult to categorize into topics. Nevertheless, we have attempted to place the papers in some order such that those dealing with the cycling and biogeochemical dynamics of carbon and the nutrient-driver elements of nitrogen and phosphorus appear first in the volume followed by those dealing with sulfur, iron and trace elements in aquatic environments, and lastly those of a more global nature. 


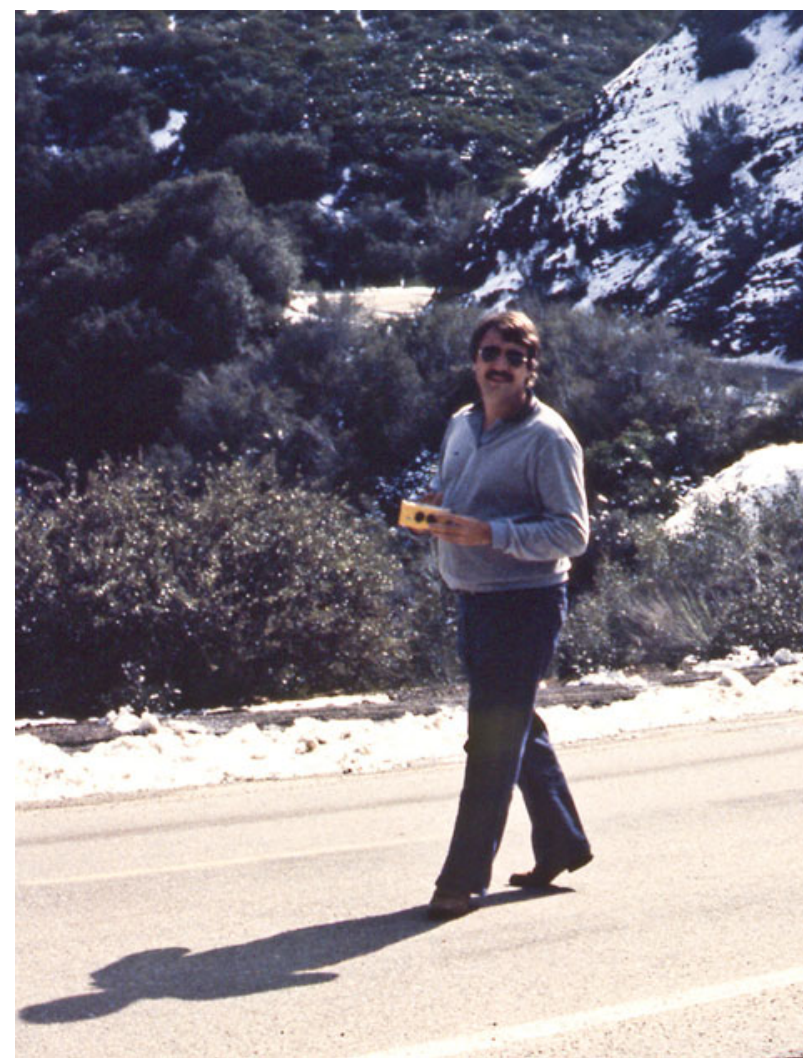

Fig. 2 The young John Morse in the Santa Ynez mountains east of Santa Barbara relaxing during a Gordon Research Conference held in Ventura, California (1983)

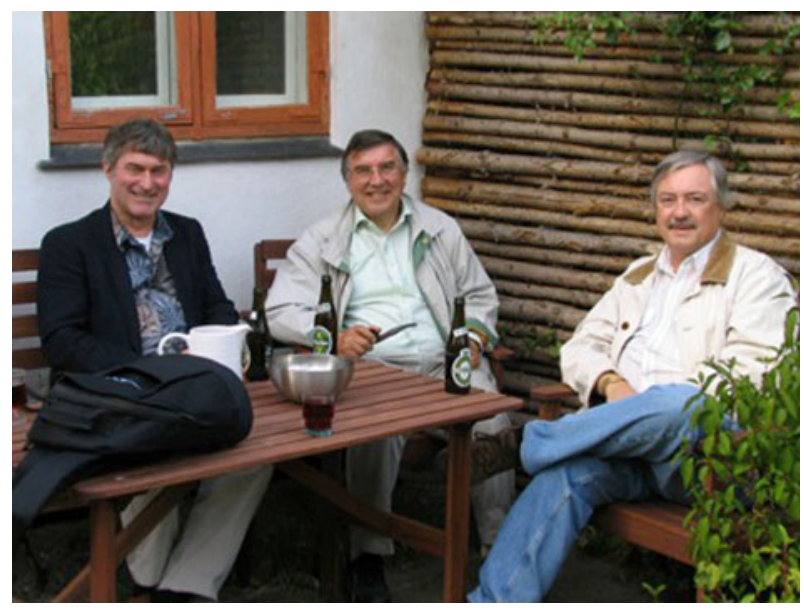

Fig. 3 From right to left; John Morse, David Rickard and George Luther discuss sulfur chemistry during a break at the Goldschmidt Conference in Copenhagen (2004) 


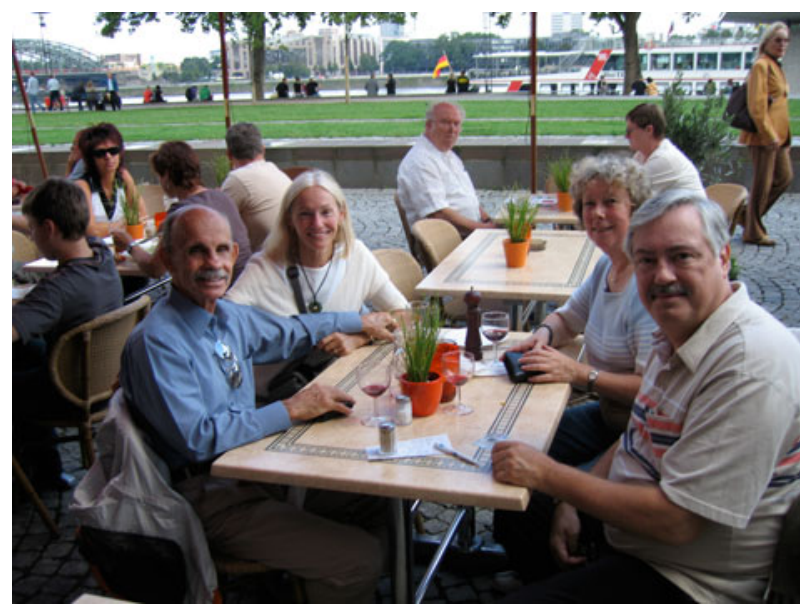

Fig. 4 From right to left: John Morse, Michele Loijens, Judy Mackenzie and Fred Mackenzie having lunch during the Goldschmidt Conference in Cologne (2007)

\section{Reference}

Mackenzie FT, Mucci A, Luther GW III (2010) In Memoriam: John W. Morse (1946-2009) Texas A\&M University. Aquat Geochem 16:219-221 